\title{
Korespondencja Ignacio Bolivara z przyrodnikami Warszawskiego Gabinetu Zoologicznego - listy Władysława Taczanowskiego, Ludwika Dembowskiego i Ludwika Młokosiewicza w zbiorach Museo Nacional de Ciencias Naturales w Madrycie
}

\section{Correspondence of Ignacio Bolivar with naturalists from the Zoological Cabinet in Warsaw - letters of Władysław Taczanowski, Ludwik Dembowski, and Ludwik Młokosiewicz in the collections of the Museo Nacional de Ciencias Naturales in Madrid}

Ignacio Bolivar, one of the most prominent entomologists of the $19^{\text {th }}$ and $20^{\text {th }}$ centuries, the Director of the National Museum of Natural History in Madrid, corresponded with naturalists associated with the Zoological Cabinet in Warsaw. The collection of the Museo Nacional de Ciencias Naturales contains the letters of Władysław Taczanowski, Ludwik Dembowski, and Ludwik Młokosiewicz. Bolivar determined orthoptera sent by Konstanty Jelski and Jan Sztolcman from South America and by Ludwik Młokosiewicz from the Caucasus. At Taczanowski's request, he sent to Warsaw the specimens of beetles and butterflies from Spain, the Iberian woodpecker and the African hymenoptera, determined by Oktawiusz Radoszkowski. Młokosiewicz's letters concern specimens of insects, reptiles, birds, and mammals sent from Georgia to Madrid as well as preparations of the Bolivar expedition to the Caucasus. Letters of Polish naturalists to Bolivar are important documents of the history of the Zoological Cabinet in Warsaw and European natural history collections in the $19^{\text {th }}$ century.

Keywords: Warsaw Zoological Cabinet, Ignacio Bolivar, Polish naturalists in South America and the Caucasus, Polish Spanish scientific exchange in the $19^{\text {th }}$ century.

Słowa kluczowe: Warszawski Gabinet Zoologiczny, Ignacio Bolivar, polscy przyrodnicy w Ameryce Południowej i na Kaukazie, polsko hiszpańska wymiana naukowa w XIX w. 
Współpraca przyrodników z Warszawskiego Gabinetu Zoologicznego z Ignacio Bolivarem była kilkakrotnie wzmiankowana zarówno w publikacjach na temat historii Gabinetu ${ }^{1}$, jak i w pracach biograficznych o Władysławie Taczanowskim² i Konstantym Jelskim³. Wiadomo było, że Bolivar oznaczał prostoskrzydłe zebrane przez Konstantego Jelskiego i Jana Sztolcmana w Peru i do tej informacji ograniczała się nasza wiedza o kontaktach Warszawskiego Gabinetu Zoologicznego z tym uczonym. Jak dotychczas nigdy jednak nie przeprowadzono kwerendy w zbiorach rękopisów biblioteki Museo Nacional de Ciencias Naturales w Madrycie. Przeprowadzone przez autora poszukiwania w archiwum Ignacio Bolivara ${ }^{4}$ dostarczają nieznanych uprzednio informacji na temat współpracy tego przyrodnika z polskimi zoologami i pokazują znaczenie przechowywanych w Madrycie listów Władysława Taczanowskiego, Ludwika Dembowskiego i Ludwika Młokosiewicza dla historii polskiej zoologii.

Ignacio Bolivar y Urrutia (1850-1944) jest niewątpliwie jednym z najwybitniejszych entomologów drugiej połowy XIX i pierwszej połowy XX w. Uznany na całym świecie specjalista prostoskrzydłych, wieloletni dyrektor madryckiego muzeum i profesor uniwersytetu odegrał także bardzo ważną role w powstaniu i organizacji licznych hiszpańskich instytucji naukowych. To właśnie głównie dzięki niemu Museo Nacional de Ciencias Naturales w Madrycie stało się jednym z najważniejszych muzeów przyrodniczych na świecie. Pionier darwinizmu, badań genetycznych w swoim krajus ${ }^{5}$ współtwórca stacji biologii morskiej, autor ponad 300 publikacji i opisów kilkuset nowych rodzajów i gatunków był uczonym bardzo wszechstronnym ${ }^{6}$. Był także demokratą, za co zapłacił wysoką cenę. Pełniąc bardzo wysokie funkcje we władzach resortu nauki Republiki Hiszpańskiej zmuszony został do wyjazdu na emigrację do Meksyku. Choć w chwili wyjazdu miał już 89 lat, także na emigracji odgrywał ważną rolę założyciela jednego z najważniejszych pism naukowych w języku hiszpańskim Ciencia: Revista hispano-americana de ciencias puras y aplicadas i przewodniczącego Towarzystwa Hiszpańskich Profesorów Uniwersyteckich $\mathrm{Na}$ Wygnaniu. Zmarł w wieku 94 lat w Meksyku, kraju do którego wyjechał’, jak sam pisał, aby „nie żyć na kolanach”. Współpraca Bolivara z Warszawskim Gabinetem Zoologicznym rozpoczęła się, jak wynika z pierwszego listu Taczanowskiego, w 1878 r. To Bolivar zwrócił się z prośbą o prostoskrzydłe z terenów Polski. Jak wynika z listu Dembowskiego,

1 J. Sztolcman, Historyczny zarys dziejów Polskiego Państwowego Muzeum Przyrodniczego, „Prace Zoologiczne Polskiego Państwowego Muzeum Przyrodniczego" t. 1, 1921, z. 1, s. 1-8.

2 A. Stępiński, Ladislas Taczanowski, „Bulletin Polonais Littéraire, Scientifique et Artistique” t. 46, 1890, s. 114117.

3 J.-C. de Massary, P. Daszkiewicz, Une collection herpétologique en Pologne peu connue en provenance d'Amérique du Sud et principalement de Guyane française, "Bulletin de la Société Herpétologique de France” 2009, nr 130-131 s. 23-38.

4 Archiwum, w tym także część korespondencji polskich przyrodników, jest obecnie dostępne on-line na stronach www.mncn.csic.es [dostęp 2.04.2019].

5 A. Martinez-Arias, A perspective on the development of Genetics in Spain during XX Century, "International Journal of Developmental Biology" t. 53, 2009, s. 1179-1191.

6 A. Gomis Blanco, Ignacio Bolivar y las ciencias naturales en Espana, Madryt 1988, s. 228.

7 Dopiero dzisiaj hiszpańscy historycy nauki oceniają rozmiar strat, jakie poniosła hiszpańska nauka w związku z emigracją Bolivara i jego współpracowników (patrz C. Martin Albaladejo, B. Sanchiz, Consequences of the Spanish Civil War for Entomology: A Quantitative Example of Abrupt Alteration in Scientific Research Dynamics, "Isis" t. 108, 2017, nr 2, s. 335-352).

8 M.G. Landa Landa, A. Briones Huerta, A. Sánchez Hernández, El legado científico del exilio español en México a través de Ciencia, „Revista Hispano-americana de ciencias puras y aplicadas” 2009, s. 87-93. 
także w 1878 r., z Bolivarem w Madrycie spotkał się Antoni Waga. Hiszpański uczony miał 27 lat, był autorem monografii prostoskrzydłych Półwyspu Iberyjskiego Sinopsis de los Ortopteros de Espana y Portugal. Rok wcześniej, w 1877 r., został mianowany profesorem.

Wymiana owadów, ich opisy i kolekcje są głównym tematem listów Taczanowskiego i Dembowskiego do Bolivara. Przesłane z Warszawy okazy były niedużą, ale ważną dla nauki kolekcją. Bolivar poświęcił im odrębną publikację․ Rezultaty badań owadów nadesłanych z Warszawskiego Gabinetu Warszawskiego przedstawił 7 września 1881 r. na posiedzeniu Sociedad Española de Historia Natural (Hiszpańskie Towarzystwo Historii Naturalnej) w referacie Estudio sobre algunos Ortópteros del Museo de Varsovia (Studium o niektórych prostoskrzydłych z Muzeum z Warszawy), w którym omówił 34 gatunki. Dzięki okazom zebranym w Ameryce Południowej przez Konstantego Jelskiego i Jana Sztolcmana opisał on nowy rodzaj Oxycercus i sześć nowych gatunków ${ }^{10}$, z których kilka zadedykował swoim polskim korespondentom, oraz ponad trzydzieści nowych stanowisk gatunków z Peru, Ekwadoru, Gujany, a także Algierii (zbiory Taczanowskiego z wyprawy z 1866 r.) i Gruzji (zbiory Ludwika Młokosiewicza). Niekiedy nowe stwierdzenia biogeograficzne miały ważne znaczenie dla zoologii. Gatunek Ectadoderus varicolor został opisany przez Henri Saussure'a w 1877 r. na podstawie egzemplarza z Muzeum w Hamburgu o nieznanym pochodzeniu. Okaz zebrany przez Sztolcmana w Lechugal w Peru pozwalał stwierdzić, że jest to gatunek południowoamerykański i to wbrew przypuszczeniom samego Saussure'a. Typy opisowe z kolekcji Bolivara w Madrycie zostały ponownie opracowane w latach dziewięćdziesiątych ubiegłego wieku. Jak wykazały te badania, w madryckiej kolekcji nadal znajduje się kilka okazów, dubletów, podarowanych Bolivarowi przez przyrodników związanych z Warszawskim Gabinetem Zoologicznym"

Owady nie były jedynym tematem korespondencji warszawskich przyrodników z Bolivarem. Podobnie jak hiszpańskiemu uczonemu zależało na wypożyczeniu okazów prostoskrzydłych z Warszawskiego Gabinetu Zoologicznego, Taczanowskiemu zależało na okazach fauny hiszpańskiej. Interesował się w tym okresie dzięciołami. O staraniach o dzięcioła z Półwyspu Iberyjskiego ${ }^{12}$ informował, w liście z 17 marca 1878 r., Antoniego Wagę:

Między ptakami Młokosiewicza znalazł się dzięcioł zielony bardzo interesujący, jest to forma dużo zmodyfikowana od typowej i przedstawia fakt bardzo ciekawy, że na trzech krańcach zielonego dzięcioła znajdują się zmodyfikowane rasy. Napisałem do Madrytu, aby mi przysłano parę tamtejszych Gecinus Sharpei ${ }^{13}$, abym mógł szczegółowo wszystkie formy porównać i opisać tego nowego. Ten dzięcioł

9 I. Bolivar, Notas entomológicas. IV. Estudio sobre algunos Ortópteros del Museo de Varsovia, "Anales de la Sociedad Española de Historia Natural" t. 10, 1881, s. 463-477.

10 Anaplecta pallida, Temnopteryx dimorpha, Ischnoptera Taczanowskii, Oxycercus peruvianus, Cyrtoxiphus Stolzmannii, Ceratinoptera dimorpha.

11 M. Paris, Catalogo de tipos de ortopteroides (Insecta) de Ignacio Bolivar. 1:Blattaria, Mantodea, Phasmoptera y Orthoptera (Stenopelmatoidea, Rhaphidophoroidea, Tettigonioidea, Grylloidea, Tetrigoidea), „Eos-Revista Espanola de Entomologia" 1994, nr 69, s. 143-264.

12 Iberyjski dzięcioł nie trafił jednak do artykułu Taczanowskiego o dzięciołach (1882). Sama informacja jest interesująca także z punktu widzenia analizy naukowych poglądów Władysława Taczanowskiego. Z jednej strony interesował się zmiennością wewnątrzgatunkową populacji z peryferii obszaru występowania, a z drugiej strony, odrzucając darwinowską koncepcję ewolucji, nie zauważał, że podobne zróżnicowanie jest jednym z mechanizmów specjacji.

13 Aktualna nazwa dzięcioła iberyjskiego to Picus sharpei (Saunders 1872), niekiedy traktowany jako podgatunek dzięcioła zielonego Picus viridis sharpei (Saunders 1872). 
kaukaski14 ${ }^{14}$ ziób ma tak zmieniony, że obyczaje jego muszą być odmienne; niezdolny jest do kucia w twardym drewnie, lecz zapewne więcej po mrowiskach grzebie $^{15}$.

Z korespondencji Taczanowskiego do Benedykta Dybowskiego (list z 4 grudnia 1879 r.) dowiadujemy się, że z Madrytu Bolivar przysłał do Warszawy afrykańskie błonkoskrzydłe, które opracowywał Oktawiusz Radoszkowski: „Generał dzielnie po cywilnemu wygląda. Ma tu już wszystkie swoje zbiory i rozpoczął pracę nad hymenopterami afrykańskimi dostawionymi mu z Madrytu"16. O tej grupie nie ma mowy w listach przechowywanych w archiwum Bolivara. Ponieważ listy hiszpańskiego uczonego do Taczanowskiego najprawdopodobniej nie zachowały się, możemy jedynie przypuszczać, że Bolivar pragnął, aby błonkoskrzydłe z madryckiej kolekcji oznaczył wybitny specjalista od tej grupy, jakim był właśnie Radoszkowski. Listy Ludwika Dembowskiego i jego stryja Floryana, informują o wielu technicznych aspektach przesyłania zbiorów entomologicznych.

Listy Młokosiewicza dostarczają wielu cennych dla historii dziewiętnastowiecznej zoologii informacji. Jak wynika z listu Taczanowskiego z 17 listopada 1879 r. to właśnie Taczanowski zwrócił się do Młokosiewicza z prośbą o zbieranie prostoskrzydłych Kaukazu. Sprzedaż okazów przyrodniczych była głównym źródłem dochodów Młokosiewicza. Nic więc dziwnego w tym, że był zainteresowany wysyłaniem okazów do Madrytu. Młokosiewicz, zgodnie z życzeniem Bolivara, przesyłał z Kaukazu nie tylko owady ${ }^{17}$, lecz także gady, ptaki i ssaki, w tym kilka szczególnie cenionych gatunków kaukaskich endemitów. Jego wysyłki były wtedy najważniejszym źródłem okazów fauny Kaukazu dla madryckiego muzeum. Z listów Młokosiewicza wynika także, iż zajmował się on przygotowaniami i organizacją przyjazdu Boliwara na Kaukaz. Do owej hiszpańskiej wyprawy do Gruzji jednak nie doszło, zapewne dlatego, że Bolivar w tym czasie wziął udział w innych wyprawach.

Przechowywane w bibliotece Museo Nacional de Ciencias Naturales w Madrycie listy polskich przyrodników są cennym źródłem informacji o historii Warszawskiego Gabinetu Zoologicznego i działalności polskich przyrodników w Ameryce Południowej oraz na Kaukazie. To także ważne źródło wiedzy o historii kolekcji i muzeów przyrodniczych, a zwłaszcza obiegu muzealnych okazów w dziewiętnastowiecznej Europie. To wreszcie cenny przyczynek do historii muzeum przyrodniczego w Madrycie i biografii Bolivara.

\section{Podziękowania}

Autor pragnie podziękować za wszechstronną pomoc i życzliwość pracownikom biblioteki i działu dokumentacji Museo Nacional de Ciencias Naturales w Madrycie, a zwłaszcza Pani del Pilar Rodríguez Luque i Panu Manuelowi Parejo Paulino.

14 Prawdopodobnie chodzi o podgatunek dzięcioła zielonego występujący w Gruzji Picus viridis karelini (Brandt 1841).

15 K. Kowalska, A. Mroczkowska, B. Zielińska, Władysław Taczanowski. Listy do Antoniego Wagi, Konstantego Branickiego i Benedykta Dybowskiego, Wrocław, Warszawa, Kraków 1964 (Memorabilia Zoologica, t. 12), s. 317.

16 Ibid., s. 157.

17 Bolivar zadedykował Młokosiewiczowi jeden z opisanych przez niego gatunków Oedaleus mlokosiewitchi. 
Bolivar I, Notas entomológicas. IV. Estudio sobre algunos Ortópteros del Museo de Varsovia, „Anales de la Sociedad Española de Historia Natural” t. 10, 1881, s. 463-477.

Gomis Blanco A., Ignacio Bolivar y las ciencias naturales en Espana, Madryt 1988.

Kowalska K., Mroczkowska A., Zielińska B., Władysław Taczanowski. Listy do Antoniego Wagi, Konstantego Branickiego i Benedykta Dybowskiego, Wrocław, Warszawa, Kraków 1964 (Memorabilia Zoologica, t. 12).

Landa Landa M.G., Briones Huerta A., Sánchez Hernández A., El legado científico del exilio español en México a través de Ciencia, „Revista Hispano-americana de ciencias puras y aplicadas" 2009, s. 87-93.

Martin Albaladejo C., Sanchiz B., Consequences of the Spanish Civil War for Entomology: A Quantitative Example of Abrupt Alteration in Scientific Research Dynamics, "Isis" t. 108, 2017, nr 2, s. 335-352.

Martinez-Arias A., A perspective on the development of Genetics in Spain during XX Century, "International Journal of Developmental Biology” t. 53, 2009, s. 1179-1191.

Massary de J.-C., Daszkiewicz P., Une collection herpétologique en Pologne peu connue en provenance d'Amérique du Sud et principalement de Guyane française, „Bulletin de la Société Herpétologique de France" 2009, nr 130-131 s. 23-38.

Paris M., Catalogo de tipos de ortopteroides (Insecta) de Ignacio Bolivar, 1: Blattaria, Mantodea, Phasmoptera y Orthoptera (Stenopelmatoidea, Rhaphidophoroidea, Tettigonioidea, Grylloidea, Tetrigoidea), „Eos-Revista Espanola de Entomologia” 1994, nr 69, s. 143-264.

Stępiński A., Ladislas Taczanowski, „Bulletin Polonais Littéraire, Scientifique et Artistique” t. 46,1890 , s. $114-117$.

Sztolcman J., Historyczny zarys dziejów Polskiego Państwowego Muzeum Przyrodniczego, „Prace Zoologiczne Polskiego Państwowego Muzeum Przyrodniczego" t. 1, 1921. z. 1, s. 1-8.

Taczanowski W., Dzięcioły, „Wszechświat” t. 1, 1882, s. 305-309, 328-329.

dr hab. Piotr Daszkiewicz, prof. PAN, jest przyrodnikiem i historykiem nauki, doktorem nauk biologicznych, doktorem habilitowanym nauk humanistycznych, profesorem w Instytucie Historii Nauki im. L. i A. Birkenmajerów PAN PAN w Warszawie, pracownikiem Office Français pour la Biodiversité, wieloletnim pracownikiem Narodowego Muzeum Historii Naturalnej w Paryżu i współpracownikiem paryskiej „Kultury” i Instytutu Literackiego w Maisons-Laffitte. Interesuje się historią nauk przyrodniczych, historią poznawania Puszczy Białowieskiej i badań nad żubrem, historią kolekcji i muzeografii przyrodniczej oraz historią polsko-francuskiej współpracy naukowej.

e-mail: piotrdas@yahoo.fr

Data zgłoszenia artykułu: 5 marca 2019

Data przyjęcia do druku: 2 kwietnia 2019 


\section{Załączniki}

Wszystkie listy zostały napisane w języku francuskim, tłum. Piotr Daszkiewicz.

\section{Listy Władysława Taczanowskiego ${ }^{18}$}

\section{Panie Profesorze!}

Jest dla mnie zaszczytem przyjęcie Pańskiej propozycji, przyjąłem ją pośpiesznie, albowiem od dawna pragnąłem nawiązać kontakt z Hiszpanią. Niestety nie będę mógł być użytecznym dla Pana, albowiem nikt u nas nie zajmuje się Pańską specjalizacją i z tego powodu prostoskrzydłe nie są dobrze reprezentowane w naszych zbiorach.

Mogę jednakże podarować Panu pewną liczbę prostoskrzydłych z Peru i z Kajenny, zebranych przez naszych podróżników i oznaczonych przez Pana de Saussure. Kilka gatunków ze wschodniej Syberii i z Kaukazu.

Jeśli chodzi o gatunki z Polski to mogę w przyszłości zorganizować ich zbiór podczas naszych wycieczek entomologicznych i dostarczyć Panu całość tego, co zostanie zebrane.

Ponieważ zajmuje się Pan w szczególności tą klasą, nie chciałby Pan, abym dostarczył Panu wszystkie prostoskrzydłe, które otrzymuję z Peru, aby je oznaczyć i opisać nowe gatunki? Mogę nawet napisać do naszych podróżników, aby zobowiązać ich do przywiązywania większej uwagi do tych owadów.

Dla nas o wiele bardziej interesujące byłoby otrzymanie chrząszczy i motyli z Hiszpanii, ponieważ interesuję się bardziej tymi dwoma rzędami.

Proszę o przyjęcie, Panie Profesorze, wyrazów najwyższego szacunku

L. Taczanowski

Warszawa 27 stycznia 1878 roku

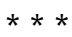

Warszawa, 14 marca $1878 \mathrm{r}$.

Panie Profesorze,

Pan Dębowski, mój współpracownik w dziedzinie entomologii, zajmuje się obecnie wyborem prostoskrzydłych dla Pana. Trochę cierpliwości i wkrótce otrzyma Pan moją pierwszą przesyłkę. Czy mógłby mi Pan przesłać pocztą Gecinus (Picus) Sharpei Saunders. $\widehat{\partial} \mathbf{i}$ †, o którym mówi się, że jest pospolity w okolicach Madrytu i Aranjuez. Będę bardzo Panu wdzięczny, ponieważ posiadam obecnie dzięcioła zielonego z Kaukazu, różnica pomiędzy nim a ptakiem z Europy Środkowej jest być może ważniejsza niż pomiędzy G. Sharpei a G. viridis Linné. Posiadając formę hiszpańską, będę w stanie lepiej ocenić cechy odróżniające formę kaukaską.

Proszę o przyjęcie wyrazów szacunku

Oddany Panu

L. Taczanowski 
Warszawa, 5 maja $1878 \mathrm{r}$.

Panie!

Przed kilkoma tygodniami przesłałem Panu moją prośbę o przesłanie mi pary Gecinus Sharpei z Hiszpanii dla porównania go z inną formą z Kaukazu, która jest nie mniej różna od Gecinus viridis z Europy Środkowej. Nie otrzymawszy odpowiedzi, proszę, aby zechciał Pan napisać, czy mogę liczyć na Pana w tej sprawie lub o udzielenie mi wskazówek, do kogo mogę się zwrócić, aby otrzymać tego ptaka.

Proszę mi wybaczyć, że prostoskrzydłe nie zostały jeszcze wysłane, są gotowe i niedługo Pan je otrzyma.

Proszę o przyjęcie wyrazów szacunku

Oddany Panu

L. Taczanowski

Warszawa, 18 maja 1878 r.

Szanowny Panie i czcigodny kolego!

Śpieszę, aby uprzedzić Pana, że prostoskrzydłe zostały wysłane pocztą, lecz nasza poczta nie chciała dać gwarancji na przesyłkę do Hiszpanii i Pan Dębowski, który ją wysłał, nie opłacił przesyłki, wierząc, że w ten sposób doręczenie będzie pewniejsze. Pan Dębowski napisze Panu informację na temat jednego z prostoskrzydłych, ale zrobi to po naszym powrocie z dwutygodniowej wycieczki entomologicznej, na którą udajemy się w dość licznym towarzystwie.

Zajmiemy się także prostoskrzydłymi dla Pana, choć pora nie jest jeszcze odpowiednia.

Proszę o przyjęcie wyrazów szacunku

Oddany Panu

L. Taczanowski

$$
* * *
$$

Warszawa, 17 listopada 1879 r.

Szanowny Panie,

Zgodnie z Pańskim życzeniem zwróciłem się do Pana Młokosiewicza, naszego zbieracza na Kaukazie, aby zebrał dla Pana prostoskrzydłe.

Właśnie otrzymałem w kopertach przesyłkę prostoskrzydłych z Gruzji i z Peru, w dobrym stanie konserwacji, wraz ze wskazaniem daty ich złapania.

Ponieważ Pan Młokosiewicz jest zmuszony do sprzedawania swoich zbiorów za gotówkę, proszę Pana o uprzedzenie mnie, czy chce je pan przyjąć na takich warunkach. Prześlę je Panu, zechce Pan je oszacować i przesłać mi ich wartość.

Od czasu gdy przesłałem Panu w maju niewielką przesyłkę, nie otrzymałem od Pana żadnych wiadomości.

Podczas ostatniego lata uzyskałem dla Pana kilka krajowych prostoskrzydłych. Otrzymałem także przesyłkę prostoskrzydłych od naszego podróżnika z Peru 
i oczekuję nadejścia innej przesyłki z tego kraju, w której być może będzie coś dla Pana.

Entomolodzy i amatorzy chrząszczy biegaczowatych ${ }^{19}$ z Warszawy pozwalają sobie przypomnieć Pańską obietnicę przysłania nam biegaczowatych z Hiszpanii, wszystkie owady z Pańskiego kraju będą dla nas bardzo interesujące.

Proszę o przyjęcie wyrazów szacunku

Oddany Panu

L. Taczanowski

\section{Korespondencja Ludwika Dembowskiego ${ }^{20}$}

Ulica Senatorska 4/459

Warszawa, 2 października 1879 r.

Szanowny Panie i Kolego,

Zajmując się w naszym muzeum wszystkim co dotyczy entomologii, pozwalam sobie tym razem zastąpić Pana Taczanowskiego - zajętego dziełem „o faunie ornitologicznej Peru" i znaczną ilością różnej korespondencji oraz licznymi innymi bardzo pilnymi zajęciami - wysyłając Panu odpowiedź na Pański bardzo miły list z 22 listopada, który został mi przekazany przez kustosza naszego muzeum.

Podjąłem się tego zadania z prawdziwą przyjemnością, tym bardziej, iż pragnąłem nawiązać korespondencyjny kontakt z tym z naszych kolegów, o którym słyszałem wiele dobrego od mojego przyjaciela i nestora naszych entomologów, profesora Wagi, który miał szczęście poznać Pana podczas swojego ubiegłorocznego pobytu w Madrycie. Chciałem przesłać panu kilka słów po wysłaniu na Pański adres niewielkiej przesyłki, zawierającej prostoskrzydłe ze Środkowego Peru, jeszcze w maju 1878, lecz bardzo pilne zajęcia nie pozwoliły mi na zrealizowanie tego zamiaru. Więc dopiero teraz śpieszę, aby wyrazić Panu tysięczne podziękowania za Pańską życzliwą obietnicę dostarczenia nam chrząszczy z Pańskiego kraju, a także oznajmić, że ponownie wysłałem Panu niewielką przesyłkę prostoskrzydłych z rosyjskiej Gruzji (Zakaukazie), zebranych przez mojego korespondenta i przyjaciela Pana Ludwika Młokosiewicza, do których dorzuciłem kilka [okazów] peruwiańskich, jak również i litewskich.

Jeśli chodzi o sposób szacunku wartości tych owadów, to przekracza to nasze kompetencje, ponieważ żaden z naszych entomologów nie zajmuje się specjalnie prostoskrzydłymi. Dlatego możemy jedynie szacować przez porównanie z cenami chrząszczy i motyli, którymi zajmuję się w szczególności. Owady wysłane przez Pana Młokosiewicza należą w większości do fauny śródziemnomorskiej, ale jest wśród nich pewna liczba gatunków perskich i syryjskich. W rezultacie czego szacujemy zazwyczaj wartość setki chrząszczy na 25-30 franków. Lecz jeśli w przesyłce znajduje się bardziej znacząca liczba gatunków pospolitych, to obniżamy wartość 100 okazów do 18-20 franków.

Otrzymaliśmy właśnie bardzo interesującą przesyłkę z Peru od naszego podróżnika Pana Stolzmanna.

Proszę o przesłanie mi Pańskiej fotografii do mojego albumu przyrodników. Będzie mi bardzo miło otrzymać Pański portret, aby umieścić go pomiędzy najsławniejszymi entomologami. 
Przed kilkoma dniami wysłałem na Pański adres broszurę, to znaczy Les diagnoses des nouvelles esp. de Lepidoptères de I'lle Askold (w Mandżurii), zebranych przez naszego podróżnika Pana Jankowskiego, opisanych przez Pana Ch. Oberthüra.

Pan Taczanowski prosił mnie o przekazanie Panu wyrazów tysięcznych podziękowań za przesłanie mu w prezencie dwóch broszur zawierających Pańskie opisy [gatunkowe].

Proszę o przyjęcie wyrazów najwyższego szacunku

Oddany Panu Ludwik Dembowski

Nb. Przesyłka wysłanych prostoskrzydłych jest opłacona aż do Madrytu.

Ja niżej podpisany Ludwik Dembowski, właściciel w Warszawie, ulica Senatorska 459, niniejszym dokumentem upoważniam Pana Floriana Dembowskiego, mojego wuja, zamieszkałego w Paryżu, ulica Mariotte 3 Batignolles, do odbioru dla mnie, od Pana Ignacio Bolivara, profesora Uniwersytetu w Madrycie, który winien mi jest kwotę sześćdziesięciu 60 franków, do przekazania pokwitowania i potwierdzenia zapłaty powyższej kwoty i w ogóle uczynienia wszystkiego, co Pan Dembowski uzna za stosowne do uzyskania odbioru kwoty.

Paryż 18 października 1880 roku

\section{Listy Ludwika Młokosiewicza21}

Łagodechy, 18 22/IV 80

Mój Drogi Panie,

Właśnie otrzymałem z Warszawy list od Pana Dembowskiego, w którym pisze, że otrzymał z Madrytu list od Pana. Pisze Pan w nim „Napiszę do Pana Młokosiewicza, przekazując mu instrukcje dotyczące polowania... i prosząc go jednocześnie o łowienie nie tylko szarańczowatych ${ }^{22}$, ale i wszelkiego rodzaju zwierząt...". Czekam na ten list i proszę o szczegółowe napisanie, czego Pan sobie życzy. Jest u nas dosyć dużo gatunków ssaków i ptaków bardzo rzadkich gdzie indziej lub takich, które spotkać można tylko na Kaukazie, jak np. Tetraogallus caucasiensis, Tetrao Mlokosiewiczi, Aegocer caucasicus i wiele innych.

Proszę Pana także o wysłanie mi, jeśli to możliwe, ryciny i opisu nowego gatunku Gomphocerus. Być może przypomnę sobie, gdzie go złowiłem i szczegółowo opiszę to, czego życzy Pan sobie wiedzieć, a co dotyczy tego gatunku.

Proszę o przyjęcie wyrazów szacunku od oddanego Panu

Mlokosievitcha

Adres

Zakaukazie przez Tyflis

Łagodechy Ludwik Mlokosievitch 
Drogi Panie,

Z prawdziwą przyjemnością odebrałem Pańską pracę Sinopsis de los ortopteros de Espana y Portugal i jestem za nią bardzo wdzięczny. Ta piękna pamiątka jest ponadto ozdobą mojej biblioteki!

Nie otrzymałem małego pudełka, o którym pisze Pan w liście z 30 maja.

Właśnie wysłałem przesyłkę do Warszawy Panu Taczanowskiemu, aby przesłana

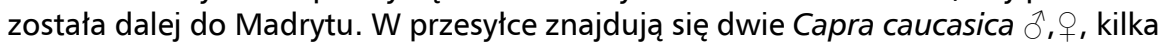
węży, myszy, pudełko z motylami, w którym znajduje się szkielet Fringilla pusilla wraz z okazem tego ptaka, który nic nie jest wart, a który przesyłam jedynie, aby pokazać Panu ten gatunek, i szkielet ryjówki z Kaukazu. Oprócz tego jest jeszcze kilka prostoskrzydłych. W tym roku zebrałem bardzo mało prostoskrzydłych, ponieważ pojawiły się przeszkody w realizacji moich podróży. Byłoby o wiele lepiej, gdyby znalazł Pan sposób transportu przesyłki bezpośrednio do Madrytu. W Tyflisie działa Maison Richard, który transportuje przesyłki, ale tylko do Marsylii. Mają 2 lub 3 parowce, La Vérité, La Meuse i wydaje mi się, że jeszcze jeden. Proszę porozumieć się z nimi, może uda się zapewnić transport bezpośrednio z Marsylii do Madrytu. Oszczędziłoby to dwa lub trzy miesiące czasu, ponieważ nasze wewnętrzne kompanie transportowe przetrzymują u siebie przesyłki przez kilka miesięcy.

Pieniądze za okazy proszę przesyłać mi bezpośrednio przez Tyflis do Łagodech, jeśli tylko jest to możliwe, a wydaje mi się, że jest, bo z Paryża otrzymuję pieniądze pocztą. Podobnie, otrzymam pieniądze dużo wcześniej, a pieniądze, przez nieszczęście bycia w potrzebie, są rzeczą dającą nam szczęśliwe godziny.

Oczekując szczęśliwej chwili czytania Pana ponawiam najserdeczniejsze pozdrowienia

Całkowicie Panu oddany

Ludwik Młokosiewicz

Rosja Zakaukazie

Przez Tyflis do Łagodech

Ludwik Mlokosevitch

Na koszty przesyłki (i transportu do Tyflisu) wydałem 12 franków. Transport z Tyflisu do Warszawy opłaci Pan Taczanowski.

Łagodechy 18 12/III 81

Drogi Panie,

Napisano do mnie z Tyflisu, że Maison Richard może przyjmować przesyłki do Madrytu przez Marsylię, gdzie zostaną one powierzone komuś innemu do dalszego transportu do Pana. Jeśli przypadkiem zna pan kogoś w Marsylii, komu można powierzyć przesyłki wysyłane na Pański adres, to wysłanie ich do Marsylii byłoby dużym ułatwieniem. Transport byłby szybszy o miesiąc lub dwa. 
Bez wątpienia otrzymał Pan już przesyłkę, którą wysłałem Panu Taczanowskiemu już 12 stycznia do Warszawy. Jeśli otrzymał ją Pan, to bardzo prosiłbym, będąc w wielkiej potrzebie, o jak najszybsze przesłanie za nią pieniędzy. Jeśli poszczęści mi się tego lata, to zrobię wszystko co możliwe, aby wysłać Panu interesującą przesyłkę.

Proszę o przyjęcie wyrazów szacunku

oddany Panu Ludwik Młokosiewicz

Rosja Zakaukazie

Przez Tyflis do Łagodech

Ludwik Mlokosevitch

Łagodechy 18 10/IV 81

Drogi Panie,

Właśnie otrzymałem Pański list, na który od razu odpowiadam. Jeśli chodzi o ceny, to jestem następującego zdania: jeśli cena różnych okazów zoologicznych jest Panu nieznana, to proszę skonsultować ją z Pana znajomymi z Uniwersytetu. Jestem pewien, że proponowana przez nich cena będzie sprawiedliwa dla obu stron. Capra caucasica lub Aegocer Caucasicus czy Aeg. Pallassii są gatunkami występującymi jedynie na Kaukazie. Nie ma ich ani w azjatyckiej części Turcji, ani w Persji, ani w Himalajach. Podobnie na Kaukazie, występuje jedynie w Wielkim Kaukazie, a jest nieobecny w Małym Kaukazie. Żyje na największych wysokościach w pobliżu śniegu i w najbardziej urwistych miejscach. Z tego powodu łowy na niego są bardzo niebezpieczne i niewielu jest amatorów podobnych polowań.

Z wielką przyjemnością mogę wysłać Towarzystwu Entomologicznemu z Madrytu to czego ono sobie życzy, ale najpierw proszę mnie poinformować, jakie są jego potrzeby.

Koszty podróży są lepsze z Marsylii do Poti. Parowce Kompanii Richarda La Meuse i La vérité płyną prosto z Marsylii do Poti, podczas gdy inne kompanie płyną jedynie do Konstantynopola, stamtąd można popłynąć rosyjskim statkiem do Poti. Podróż na tym drugim drugą klasą z Konstantynopola do Poti kosztuje 30 rubli. Z Poti pokonuje się trasę w 5 lub 6 dni. Koleją z Poti do Tyflisu, 300 km, w 10 godzin. Za tę ostatnią płaci się 10 rubli. Z Tyflisu do Łagodech jest około $200 \mathrm{~km}$ i pocztowymi końmi dociera się w 24 godziny, kosztuje to 18 rubli. Życie w Tyflisie jest dość drogie, jest ono droższe niż gdziekolwiek indziej w Europie, lecz w przypadku wielkiej podróży ta drożyzna to bagatela. Jeśli przyjedzie Pan do Łagodech, to będzie Pan u mnie mile widzianym gościem i będę szczęśliwym móc się z Panem spotkać. Mogę tutaj towarzyszyć Panu w wędrówkach i mogę być użytecznym, rozumiejąc trochę języki kraju, lecz jeszcze bardziej znając interesujące miejsca. Nie wiem, czy okoliczności pozwolą mi pojechać z Panem gdzie indziej. Maj jest najlepszą porą łowów chrząszczy, dla prostoskrzydłych i pluskwiaków miesiąc czerwiec i później.

Proszę o przyjęcie wyrazów szacunku

oddany Panu

Ludwik Młokosiewicz 
Rosja Zakaukazie

Przez Tyflis do Łagodech

Ludwik Mlokosevitch

Jeżeli uda się Pan w podróż to proszę mnie poinformować o Pańskim wyjeździe i dotarłszy do Poti, proszę wysłać mi telegram do Łagodech, abym był w domu.

\section{Listy Floryana Dembowskiego ${ }^{23}$}

\section{Panie}

Proszę o wybaczenie, iż przypominam niewielki dług, jaki zaciągnął Pan wobec mojego bratanka. Pana Ludwika Dembowskiego w Warszawie, około [brak wyrazu]. Uczyni mi Pan przyjemność odpowiadając, kiedy będzie mógł Pan zwrócić mi 60 franków, które jest mu Pan winien, abym mógł liczyć na te pieniądze. Będę oczekiwał przez okres, który zechce Pan osobiście wyznaczyć, o ile nie będzie zbyt długi. Żałuję bardzo, że jestem zmuszony wywierać w ten sposób nacisk na Pana, lecz zapewniam Pana, że nie mam innej możliwości działania.

Mam zaszczyt wyrazić Panu wyrazy najwyższego uznania

Oddany Panu

Floryan Dembowski

3 Rue Mariotte Batignolles

Paryż 3 października 1880

Panie

Właśnie otrzymałem Pański miły list z 2 stycznia i śpieszę, by Panu odpowiedzieć. Rozpocznę od tego, by poinformować Pana, że mój bratanek po sześciotygodniowym pobycie w Paryżu opuścił to miasto w listopadzie, aby udać się do Włoch. Zupełnie nie wiem, kiedy powróci do Warszawy. Jeśli chodzi o niewielką kwotę 60 franków, o której jest mowa, to najpewniejszym środkiem jest przesłanie jej pocztą lub telegrafem, tutaj do Juvissie Départ Seine et Oise.

Proszę o przyjęcie wyrazów najwyższego szacunku

Oddany Panu

Floryan Dembowski

Juvissi 8 lutego 1881

Départ Seine et Oise 
Panie

W mojej odpowiedzi na Pański miły list z 2 stycznia zapomniałem napisać Panu, że w pierwszym tygodniu najbliższego marca opuszczam Paryż i Francję, być może na zawsze, aby powrócić do mojego kraju, do Warszawy.

Tak więc mam zaszczyt uprzedzić Pana, iż jeśli życzy sobie Pan, aby ta niewielka kwota dotarła do mnie, to zobowiązuję Pana do szybkiego przesłania jej pocztą lub telegrafem, jak Panu będzie wygodniej.

Proszę o przyjęcie wyrazów najwyższego szacunku

Oddany Panu

Floryan Dembowski, Inżynier na emeryturze

Juvissi 8 lutego 1881

Départ Seine et Oise lub 3 Rue Mariotte Batignolles 